\title{
Germinação e expressão morfológica de frutos, sementes e plântulas de Pilosocereus pachycladus Ritter ${ }^{1}$
}

\author{
Germination and morphological expression of Pilosocereus pachycladus Ritter fruits, \\ seeds and seedlings
}

\author{
Haynna Fernandes Abud ${ }^{2 *}$, Nayara Roberto Gonçalves ${ }^{3}$, Rodrigo de Góes Esperon Reis ${ }^{3}$, Diego de Sousa \\ Pereira $^{4}$ e Antonio Marcos Esmeraldo Bezerra ${ }^{5}$
}

\begin{abstract}
Resumo - Objetivou-se apresentar resultados sobre a morfologia de frutos, sementes, bem como a germinação e a descrição de estádios de crescimento das plântulas de Pilosocereus pachycladus. As sementes utilizadas foram obtidas de frutos colhidos na Fazenda Experimental Vale do Curu, em Pentecoste - CE. Foram utilizados 10 frutos para realização das determinações biométricas e morfológicas. Para a descrição da morfologia das sementes consideraram-se os aspectos externos e internos. Foram testadas duas condições de luminosidade (fotoperíodo de 12 horas e escuro completo) e três temperaturas $\left(25 ; 30\right.$ e $\left.20-30{ }^{\circ} \mathrm{C}\right)$ dispostas num arranjo fatorial 2 × 3 , no modelo inteiramente casualizado com quatro repetições de 50 sementes cada. Efetuaram-se contagens diárias até o $16^{\circ}$ dia após a semeadura para avaliar: porcentagem e índice de velocidade de germinação. Para a descrição e ilustração da morfologia externa da plântula, foi realizada a semeadura de 200 sementes em bandeja de polietileno. Avaliaramse os processos de germinação e crescimento das plântulas de facheiro durante um período de 150 dias, sendo caracterizados oito estádios de desenvolvimento, que foram baseados nas diferenças morfológicas observadas. Conclui-se que o fruto apresenta comprimento de $38,13 \mathrm{~mm}$, espessura de $50,53 \mathrm{~mm}$ e 3786 sementes. As sementes de facheiro comportam-se como fotoblástica positivas e as temperaturas constantes de 25 e $30^{\circ} \mathrm{C}$ proporcionaram as maiores porcentagens e velocidades de germinação. Após 150 dias da semeadura a planta encontra-se com epicótilo em crescimento, com presença de grande quantidade de espinhos, e com $94,31 \mathrm{~mm}$ de comprimento.
\end{abstract}

Palavras-chave - Cactaceae. Facheiro. Caracterização morfológica. Crescimento.

\begin{abstract}
It was aimed to present the results on the germination, morphology of fruits, seeds and description of stages of plant growth of Pilosocereus pachycladus. The seeds were obtained from fruits harvested at the Curu Valley Experimental Farm, in Pentecoste - CE. Ten fruits were used to the realization of the biometric and morphological determinations. For description of the morphology of the seeds, were considered the external and internal aspects. Two light conditions (12 hours photoperiod and total darkness) and three temperatures $\left(25 ; 30\right.$ and $\left.20-30^{\circ} \mathrm{C}\right)$ were tested in a factorial arrangement $2 \times 3$ arranged in a completely randomized design with four replications of 50 seeds each. Counts were done daily until the $16^{\text {th }}$ day after sowing and to evaluated: the percentage and velocity index of germination. For description of the morphology of the seeds, were considered the external and internal aspects. For description and illustration of the external morphology of germination and seedling, were sowed 200 seeds in a polyethylene tray. The processes of germination and seedling growth were evaluated during 150 days and eight stages of development were characterized and those were based on morphological differences observed. It was concluded that, the fruit measures $38.13 \mathrm{~mm}$ of length, $50.53 \mathrm{~mm}$ of thickness and 3786 seeds. The constant temperatures of $25{ }^{\circ} \mathrm{C}$ and $30{ }^{\circ} \mathrm{C}$ under a photoperiod of 12 hours made possible the highest percentages and velocities of germination and the seeds behave as photoblastic positive. 150 days after sowing, the epicotyl is growing with a large amount of thorns and $94.31 \mathrm{~mm}$ of length.
\end{abstract}

Key words - Cactaceae. Facheiro. Morphological characterization. Growth.

\footnotetext{
* Autor para correspondência

${ }^{1}$ Recebido para publicação em 08/09/2009; aprovado em 20/07/2010

Pesquisa financiada pelo $\mathrm{CNPq}$

${ }^{2}$ Programa de Pós-Graduação em Fitotecnia, UFV, hfabud@gmail.com

3Programa de Pós-Graduação em Fitotecnia, DAG/UFLA, Lavras-MG, Brasil, nayararob1@gmail.com, guidegoes@gmail.com

${ }^{4}$ Graduando em Zootecnia, CCA/UFC, Fortaleza-CE, Brasil, diegobizi@gmail.com

${ }^{5}$ Departamento Fitotecnia, CCA/UFC, Fortaleza-CE, Brasil, esmeraldo@ufc.br
} 


\section{Introdução}

O Brasil é considerado o terceiro maior centro de diversidade da família Cactaceae, totalizando aproximadamente 200 espécies (SOUZA; LORENZI, 2005), sendo muitas destas espécies endêmicas da Caatinga Nordestina, e que necessitam de maiores estudos (TAYLOR; ZAPPI, 2004).

As cactáceas constituem um importante elemento da paisagem, apresentando caules suculentos, áfilos, cobertos por espinhos de diversas formas, tamanhos e dimensões (SOUZA; LORENZI, 2005). O facheiro (Pilosocereus pachycladus) é uma espécie desta família de abrangente ocorrência no Semi-árido Nordestino (BRAGA, 1976). É uma planta perene, arbustiva, robusta, de tronco ereto com galhos laterais, porém pouco ramificada, de coloração verde escura, que apresentam espinhos agudos e flores grandes, alvas e isoladas (BRAGA, 1976). Os frutos são consumidos por pássaros e as sementes são dispersas pela avifauna. A propagação das cactáceas pode ser realizada de forma sexuada ou assexuada, sendo a primeira um método ainda pouco utilizado devido à escassez de informações nesta área de conhecimento. Na propagação sexuada as plântulas crescem lentamente, mas podem ser produzidas em grande quantidade, além de proporcionar variações genéticas importantes, apresentando diversas características morfológicas desejáveis, o que é apreciado do ponto de vista ornamental.

A temperatura exerce papel importante no processo de germinação, agindo sobre a velocidade de absorção de água, e nas reações bioquímicas (MARCOS FILHO, 2005). A temperatura ótima propicia a máxima porcentagem de germinação em menor tempo, enquanto sob temperatura máxima e mínima as sementes apresentam baixa germinabilidade. Para sementes de cactáceas as temperaturas favoráveis situam-se entre 15 e $35{ }^{\circ} \mathrm{C}$. Rojas-Aréchiga e Vásquez-Yanes (2000) asseguram que a temperatura ótima para germinação de suas sementes de cactáceas está em torno $25^{\circ} \mathrm{C}$. Aspectos relacionados à germinação e caracterização morfológica de frutos, sementes e plântulas, em cactáceas, particularmente, de espécies nativas brasileiras são escassos na literatura, porém existem informações sobre algumas espécies, tais como Stenocereus stellatus (ROJAS-ARECHIGA et al., 2001), Stenocereus queretaroensis (BARRERA; NOBEL, 2003; LOZA-CORNEJO et al., 2003), Melocactus bahiensis (LONE et al., 2007), Trichocereus terscheckii (ORTEGA-BAES; ROJAS-ARECHIGA, 2007), Denmoza rhodacantha (MÉNDEZ, 2007), Hylocereus setaceus (SIMÃO et al., 2007), Hylocereus undatus (ANDRADE et al., 2005; ANDRADE etal., 2008) e Cereus fernambucensis, Coleocephalocereus fluminensis, Pilosocereus arrabidae e Pilosocereus ulei (ALMEIDA et al., 2009).
O conhecimento das características morfológicas das sementes é importante para manutenção da biodiversidade, bem como é uma ferramenta para a compreensão e descrição do processo germinativo (OLIVEIRA et al., 2006). O estudo dos aspectos morfológicos da germinação, além de contribuir para a propagação das espécies, aborda a classificação da germinação em relação à posição dos cotilédones, auxiliando na interpretação e padronização dos testes de germinação, contribuindo para o conhecimento morfoanatômico integral da espécie (BELTRATI, 1995). A combinação dos caracteres da semente e da plântula pode fornecer subsídios necessários ao reconhecimento das espécies no campo e em amostras de sementes (BELTRATI, 1995). A caracterização biométrica de frutos e de sementes pode fornecer informações importantes que contribuem para auxiliar a diferenciação de espécies do mesmo gênero (CRUZ et al., 2001).

Diante da escassez de informações sobre a propagação sexuada de facheiro, objetivou-se neste trabalho apresentar resultados sobre a morfologia de frutos, sementes, bem como a germinação e a descrição dos estádios de crescimento de plantas de Pilosocereus pachycladus.

\section{Material e métodos}

As sementes de facheiro utilizadas no experimento foram obtidas de frutos maduros, colhidos de exemplares existentes na Fazenda Experimental Vale do Curu, da Universidade Federal do Ceará (UFC), localizada em Pentecoste - CE. Após a colheita os frutos foram acondicionados em sacos plásticos e transportados para o Laboratório de Análises de Sementes (UFC). Foram realizadas determinações biométricas (comprimento, diâmetro, número de sementes por fruto) e morfológicas dos frutos, para isto, foram utilizados 10 frutos. Considerou-se como comprimento a região compreendida entre a base e o ápice, enquanto o diâmetro foi mensurado na parte intermediária dos frutos. Nas avaliações citadas utilizou-se paquímetro digital da marca Starret $727 \AA$, com resolução de 0,01 mm. Procedeu-se o cálculo das seguintes estatísticas descritivas: média, desvio padrão, coeficiente de variação e intervalo de confiança dos valores obtidos. Para a descrição da morfologia dos frutos considerou-se os aspectos externos como tipo, formato, coloração do epicarpo e número de sementes.

Posteriormente, foi realizada a extração das sementes mediante a abertura dos frutos e retirada da polpa através de maceração com o auxílio de uma peneira e lavagem em água corrente. Em seguida, as sementes foram postas para secar à sombra, durante dois dias. Para a descrição da morfologia das sementes foram utilizadas 50 unidades, escolhidas 
aleatoriamente. Consideraram-se os aspectos externos (tipo, forma, estrutura da testa, coloração, posição do hilo e da micrópila) e internos (embrião e tecido de reserva). Para as observações morfológicas internas, as sementes foram previamente imersas em água destilada por 24 horas, para amolecimento e hidratação dos tecidos. Após este período realizaram-se cortes longitudinais com lâmina metálica e em seguida foram observados em lupa INALH - MLS 250.

Seguindo a metodologia descrita nas Regras para Análises de Sementes (RAS) realizou-se a determinação do teor de água e determinação do peso de mil sementes (BRASIL, 2009).

Nos estudos da germinação foram testadas duas condições de luminosidade (fotoperíodo de 12 horas e escuro completo) e três regimes de temperatura (25; 30 e $20-30{ }^{\circ} \mathrm{C}$ ) dispostos num arranjo fatorial $2 \times 3$, no modelo inteiramente casualizado com quatro repetições de 50 sementes cada. As sementes foram dispostas em placas de Petri, com folha dupla de papel de filtro, umedecidas com água destilada na proporção de 2,5 vezes o peso do papel seco (BRASIL, 2009). Foram consideradas germinadas as sementes que originaram plântulas com radícula de comprimento igual ou maior que um milímetro. Para verificar o efeito da temperatura e luminosidade efetuaram-se contagens diárias até 0 $16^{\circ}$ dia após a semeadura para obtenção das seguintes variáveis: porcentagem de germinação - realizada através da contagem de plântulas normais de cada unidade experimental, com os resultados expressos em porcentagem; índice de velocidade de germinação (IVG) - foram feitas contagens diárias das sementes germinadas, adotando-se a metodologia recomendada por Maguire (1962). As sementes mantidas no escuro foram observadas sob luz verde de segurança. Os dados foram submetidos à análise de variância e a comparação das médias foi realizada pelo teste de Tukey, ao nível de 5\% de probabilidade (BANZATTO; KRONKA, 2006).

Para descrição e ilustração da morfologia externa da plântula, foi realizada a semeadura de 200 sementes em bandeja de polietileno, contendo vermiculita e húmus como substrato, na proporção de 1:1 (v/v), mantidas sob condições de casa de vegetação (sombreamento de $50 \%$, temperatura média de $29,6{ }^{\circ} \mathrm{C}$ e umidade relativa de $60 \%$ ) e irrigação intermitente. Avaliou-se o processo de germinação e crescimento das plântulas de facheiro durante um período de 150 dias, sendo caracterizados oito estádios de desenvolvimento, que foram baseados nas diferenças morfológicas observadas. Para a caracterização das plântulas foram selecionadas as mais vigorosas, sendo evidenciados: sistema radicular, colo, epicótilo e hipocótilo, de acordo com Barroso et al. (1999) e Beltrati (1995). Os aspectos morfológicos externos das sementes e das plântulas foram ilustrados manualmente.

\section{Resultados e discussão}

Observou-se que os frutos de facheiro apresentam epicarpo de coloração verde durante a sua maturação (FIG. 1A) e após atingir a maturidade fisiológica apresentam coloração lilás (FIG. 1B). São do tipo baga, polispérmicos, deiscentes, carnosos, apresentando pericarpo espesso e suculento.

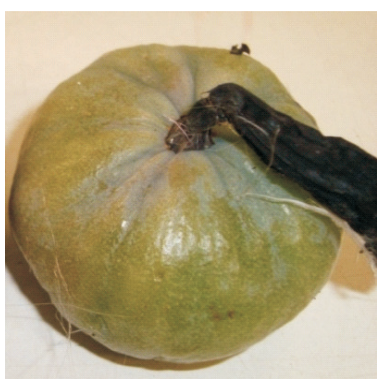

A

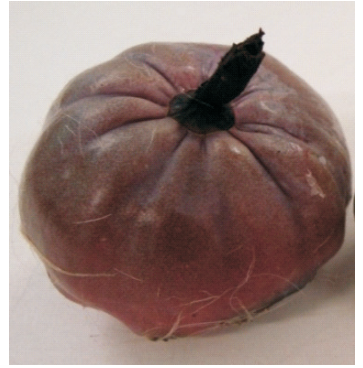

B
Figura 1 - Aspectos externos do fruto de facheiro verde (A) e maduro (B). Fortaleza-CE, 2009

Na Tabela 1 está inserida a estatística descritiva referente à biometria dos frutos. Pode-se verificar que o fruto de facheiro apresentou 38,13 $\pm 4,52 \mathrm{~mm}$ de comprimento e $50,53 \pm 5,01 \mathrm{~mm}$ de espessura e com $3786,10 \pm 489,42$ sementes por fruto. Verificou-se que o número de sementes por fruto apresentou a maior dispersão relativa, como denota o seu coeficiente de variação. Rojas-Aréchiga e Vázquez-Yanes (2000) afirmam que o número de sementes produzidas por fruto pode variar bastante dependendo da espécie. Esses autores relatam em sua revisão haver diferença no número de sementes por fruto mesmo dentro da própria espécie, dependendo da idade, do tamanho da planta, entre outros fatores.

As sementes de cactáceas podem apresentar diversas formas, cores, aparências e tamanhos (ROJASARÉCHIGA; VÁSQUEZ-YANES, 2000). As sementes de facheiro são estenospérmicas, exalbuminosas, sendo seu formato ligeiramente obovado-oblíqua, a testa é rugosa e apresenta coloração preta (FIG. 2A e B). As sementes são campilótropas, exotestais, bitegumentadas. O embrião é facilmente observado quando a semente está hidratada, apresenta coloração branca e ocupa quase todo espaço da semente, é cilíndrico e grande. Apresenta tecido de reserva cotiledonar, de coloração branca, e consistência firme. Os cotilédones são plano-convexos, estreitos (FIG. 2C). 
Tabela 1 - Caracterização dos frutos de facheiro em função do comprimento, diâmetro e número de sementes. Fortaleza-CE, 2009

\begin{tabular}{cccc}
\hline Características & Média $^{1}$ & Desvio Padrão & CV (\%) \\
\hline Comprimento $(\mathrm{mm})$ & $38,13 \pm 4,52$ & 7,29 & 19,11 \\
Diâmetro $(\mathrm{mm})$ & $50,53 \pm 5,01$ & 8,08 & 15,98 \\
Número de sementes & $3786,10 \pm 489,42$ & 789,63 & 20,86 \\
\hline
\end{tabular}

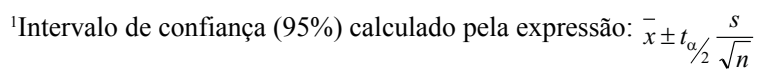

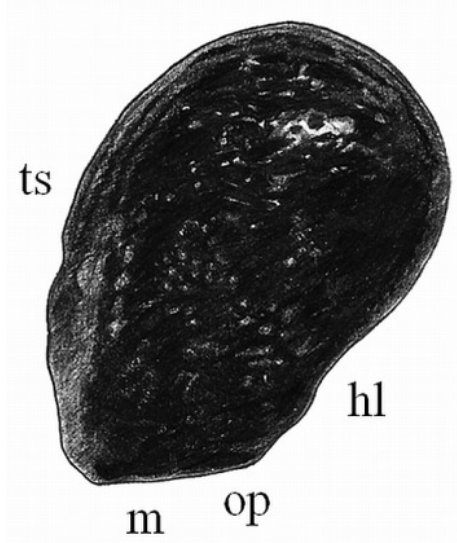

A

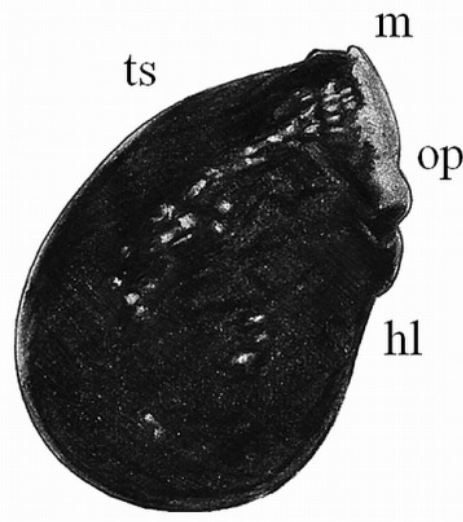

B

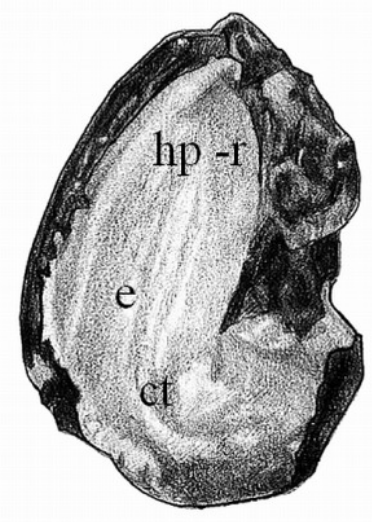

C

Legenda: e- embrião, hl- hilo, m- micrópila, op- opérculo, ts- testa, ct- cotilédones, hp-r- eixo hipocótilo- radícula

Figura 2 - Caracterização morfológica das sementes de facheiro. A e B- aspectos externos C - aspectos internos. Fortaleza-CE, 2009

O peso de mil sementes do facheiro foi em média de $1,356 \mathrm{~g}$, o que permite inferir que uma grama de sementes de facheiro contém aproximadamente 737 sementes. O teor de água deste lote de sementes foi de 10,3\%. Marcos Filho (2005) afirma que o teor de água das sementes é um fator que interfere diretamente no peso das sementes, variando de acordo com as condições do local de colheita, com a idade e maturação das sementes.

O resumo da análise de variância com os coeficientes de variação para germinação e índice de velocidade de germinação encontram-se na Tabela 2 . Pode-se verificar que houve interação entre os fatores luz e temperatura, ao nível de $5 \%$ de probabilidade para as variáveis analisadas.

Na Tabela 3 estão expostos os valores médios de porcentagem e índice de velocidade de germinação. Pode-se observar que a porcentagem de germinação variou em função da temperatura. Os melhores resultados de porcentagem e velocidade de germinação foram observados nas temperaturas de $25{ }^{\circ} \mathrm{C}(98 \%$ e 6,4$)$ e $30{ }^{\circ} \mathrm{C}(92 \%$ e 7,0$)$ sob fotoperíodo de 12 horas (Tabela 3). Resultados semelhantes foram observados por Lone et al. (2007) na germinação de Melocactus bahiensis, na qual a temperatura de $25{ }^{\circ} \mathrm{C}$ proporcionou maiores porcentagens e índice de velocidade de germinação. Estudos feitos com Astrophytum myriostigma indicam que a $10{ }^{\circ} \mathrm{C}$ não ocorre germinação, entre 15 e $25^{\circ} \mathrm{C}$ apresenta máxima germinação e acima de $30^{\circ} \mathrm{C}$, a taxa de germinação é reduzida consideravelmente (ROJAS-ARÉCHIGA; VÁSQUEZ-YANES, 2000). Estudos recentes têm demonstrado que a luz estimula a germinação de algumas espécies de cactáceas, indicando que estas são fotoblásticas positivas (ORTEGA-BAES; ROJAS-ARÉCHIGA， 2007; ROJAS-ARÉCHIGA; VÁSQUEZ-YANES, 2000). As sementes de facheiro, quando submetidas ao escuro pleno, apresentaram ausência total de germinação em todas as temperaturas avaliadas, comportando-se, portanto, como fotoblástica positiva. Esse resultado corrobora com os obtidos por Benítez-Rodrígues et al. (2004) estudando o efeito da luz na germinação de quatro espécies do gênero Mammillaria, que observaram que as sementes são 
Tabela 2 - Resumo da análise de variância para os efeitos da combinação de duas condições de luminosidade (fotoperíodo de 12 horas e escuro completo) e três temperaturas $\left(25 ; 30\right.$ e $\left.20-30^{\circ} \mathrm{C}\right)$ para porcentagem e índice de velocidade de germinação (IVG) de sementes de facheiro. Fortaleza-CE, 2009

\begin{tabular}{cccc}
\hline \multirow{2}{*}{ FV } & GL & \multicolumn{2}{c}{ Quadrados Médios } \\
\cline { 3 - 4 } & & Germinação (\%) & IVG \\
\hline Temperatura (T) & 2 & $72,00^{*}$ & $3,91^{*}$ \\
Luz (L) & 1 & $50784,00^{* *}$ & $207,85^{* *}$ \\
T x L & 2 & $72,00^{*}$ & $3,91^{*}$ \\
Resíduo & 18 & 17,77 & 0,32 \\
\hline CV (\%) & - & 9,17 & 19,24 \\
\hline
\end{tabular}

** Significativo ao nível de $1 \%$ de probabilidade; * Significativo ao nível de $5 \%$ de probabilidade

Tabela 3 - Médias da porcentagem de germinação e índice de velocidade (IVG) de sementes de facheiro submetidas a três regimes de temperatura sob fotoperíodo de 12 horas. Fortaleza-CE, 2009

\begin{tabular}{ccl}
\hline Temperaturas & Germinação & IVG \\
\hline $25^{\circ} \mathrm{C}$ & $98 \mathrm{~A}$ & $6,4 \mathrm{~A}$ \\
$30^{\circ} \mathrm{C}$ & $92 \mathrm{AB}$ & $7 \mathrm{~A}$ \\
$20-30{ }^{\circ} \mathrm{C}$ & $86 \mathrm{~B}$ & $4,3 \mathrm{~B}$ \\
\hline $\mathrm{DMS}$ & 7,61 & 1,02 \\
\hline
\end{tabular}

Médias seguidas pela mesma letra não diferem estatisticamente entre si, pelo teste de Tukey, a $5 \%$ de probabilidade

fotoblásticas positivas, e que para todas as espécies os melhores resultados de germinação foram obtidos na temperatura constante de $25{ }^{\circ} \mathrm{C}$. Resultados diferentes foram observados em sementes de Dyckia tuberosa (Bromeliaceae), na qual a germinação de sementes pode ocorrer também em ambientes com a ausência completa de luz, comportando-se como fotoblástica neutra (VIEIRA et al., 2007). Em virtude da ausência de germinação sob condição de escuro pleno computaramse para efeito de análise os resultados obtidos sob fotoperíodo de 12 horas.

$\mathrm{Na}$ Figura 3, pode-se observar oito estádios de crescimento de facheiro registradas a partir das modificações morfológicas apresentadas até os 150 dias após a semeadura. A semente de facheiro apresenta comprimento médio de 1,55 mm (FIG. 3A). Observou-se que aproximadamente 96 horas após a semeadura ocorreu a protrusão radicular, através da abertura do opérculo (FIG. 3B). Esta estrutura cresce rapidamente, e aos seis dias após a semeadura observou-se um comprimento médio de 1,98 $\mathrm{mm}$ (FIG. 3C). Posteriormente, ocorreu o desenvolvimento do hipocótilo, que com 10 dias após a semeadura, encontrava-se com aproximadamente $12 \mathrm{~mm}$ de comprimento, observando-se também o aparecimento de pêlos radiculares (FIG. 3D). Decorridos 13 dias após a semeadura verificou-se a liberação completa do tegumento, que até então encontrava-se aderido aos cotilédones (FIG. 3D), havendo abertura progressiva dos cotilédones. Neste momento o hipocótilo encontrava-se completamente ereto, com cerca de $15 \mathrm{~mm}$ de comprimento (FIG. 3E). Após 30 dias da semeadura observou-se o aparecimento de cerdas entre os cotilédones (FIG. 3F). O desenvolvimento do epicótilo demonstrou-se bastante lento, ocorrendo aproximadamente 60 dias após a semeadura (FIG. 3G). Aos 90 dias após a semeadura observou-se grande quantidade de espinhos e o crescimento do epicótilo, onde a partir daí as modificações morfológicas encontradas não foram expressivas, ocorrendo apenas o aumento de tamanho das plântulas, até os 150 dias após a semeadura (FIG. 3H). 


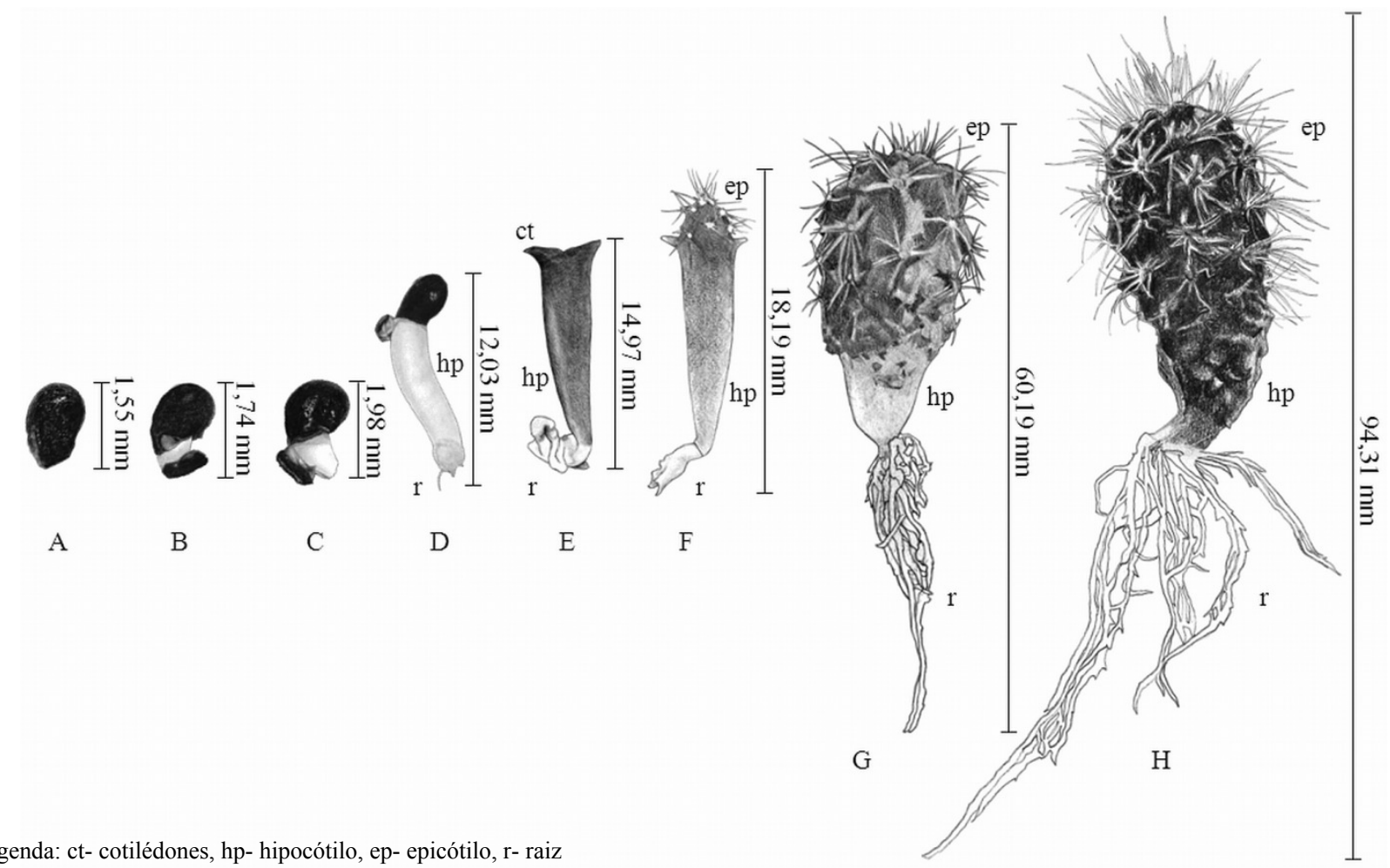

Figura 3 - Aspectos morfológicos da semente e diferentes estádios de crescimento de facheiro até os 150 dias após a semeadura. Fortaleza - CE, 2009.

\section{Conclusões}

1. O fruto de facheiro apresenta em média comprimento de $38,13 \mathrm{~mm}$, diâmetro de $50,53 \mathrm{~mm}$ e 3.786 sementes;

2. As sementes de facheiro se comportam como fotoblástica positiva e as temperaturas constantes de 25 e $30^{\circ} \mathrm{C}$ proporcionam as maiores porcentagens e velocidades de germinação;

3. Após 150 dias da germinação a planta de facheiro encontra-se com epicótilo em crescimento, com presença de grande quantidade de espinhos, com 94,31 mm de comprimento.

\section{Referências}

ALMEIDA, T. M. H.; ANDRADE, A. C. S.; LOPES, H. M. Brazilian cacti seed germination under different temperature and substrate conditions. Seed Science \& Technology, v. 37, n. 02, p. 474-479, 2009.

ANDRADE, R. A.; OLIVEIRA, I. V. M.; MARTINS, A. B. G. Influência da condição e período de armazenamento na germinação de sementes de Pitaya vermelha. Revista Brasileira de Fruticultura, v. 27, n. 01, p. 168-170, 2005.
ANDRADE, R. A. et al.. Germinação de Pitaya em diferentes substratos. Revista Caatinga. v. 21, n. 01, p. 71-75, 2008.

BANZATTO, D. A.; KRONKA, S. N. Experimentação agrícola. 4. ed. Jaboticabal: FUNEP/UNESP, 2006. 237 p.

BARRERA, E. D.; NOBEL, P. S. Physiological ecology of seed germination for the columnar cactus Stenocereus queretaroensis. Journal of Arid Environments, v. 53, n. 03, p. 297-306, 2003.

BARROSO, G. M. et al.. Frutos e sementes: morfologia aplicada à sistemática de dicotiledôneas. Viçosa: UFV, 1999. 443 p.

BELTRATI, C. M. Morfologia e anatomia de sementes. In: CURSO DE PÓS- GRADUAÇÃO EM CIÊNCIAS BIOLÓGICAS, ÁREA DE BIOLOGIA VEGETAL. Rio Claro: Departamento de Botânica / Instituto de Biociências /UNESP, 1995. 98 p. Apostila.

BENÍTEZ-RODRÍGUEZ, J. L.; OROZCO-SEGOVIA, A.; ROJAS-ARÉCHIGA, M. Light effect on seed germination of four Mammillaria species from the Tehuacán-Cuicatlán Valley, Central Mexico. The Southwestern Naturalist, v. 49, n. 01, p. 11-17, 2004.

BRAGA, R. Plantas do Nordeste, especialmente do Ceará. 3. ed. Mossoró: Escola Superior de Agricultura de Mossoró, 1976. 510 p.

BRASIL. Ministério da Agricultura e Reforma Agrária. Regras para análises de sementes. Brasília: SNDA/ DNDV/CLAV, 2009. $399 \mathrm{p}$. 
CRUZ, D. E.; MARTINS, F. O.; CARVALHO, J. E. U. Biometria de frutos e sementes e germinação de jatobá-curuba (Hymenea intermedia Ducke, Leguminosae, Caesalpinoideae). Revista Brasileira de Botânica, v. 24, n. 02, p. 161-165, 2001.

LABOURIAU, L. G. A germinação das sementes. Washington, D.C.: Secretaria Geral da OEA, 1983. 147 p.

LONE, A. B. et al.. Germinação de Melocactus bahiensis (CACTACEAE) em diferentes substratos e temperaturas. Scientia Agrária, v. 08, n. 04, p. 365-369, 2007.

LOZA-CORNEJO, S.; TERRAZAS, T.; LOPEZ-MATA, L. et al. Características morfo-anatómicas y metabolismo fotosintético en plántulas de Stenocereus queretaroensis (Cactaceae): su significado adaptativo. Interciencia, v. 28, n. 02, p. 83-89, 2003.

MARCOS FILHO, J. Fisiologia de sementes de plantas cultivadas. Piracicaba: FEALQ, 2005. 495 p.

MAGUIRE, J. D. Speed of germination-aid in selection and evaluation for seedling emergence and vigor. Crop Science, v. 02, n. 01, p. 176-177, 1962.

MÉNDEZ, E. Germination of Demonza rhodacantha (Salm-Dyck) Britton \& Rose (Cactaceae). Journal of Arid Environments, v. 68, p. 678-682, 2007.

OLIVEIRA, A. K. M.; SCHLEDER, E. D.; FAVERO, S. Caracterização morfológica, viabilidade e vigor de sementes de Tabebuia aurea (Silva manso) Benth. \& Hook. F. ex. S. Moore. Revista Árvore, v. 30, n. 01, p. 25-32, 2006.
ORTEGA-BAES, P.; ROJAS-ARÉCHIGA, M. Seed germination of Tricocereus terscheckii (Cactaceae): Light, temperature and giberellinic acid effects. Journal of Arid Environments, v. 69, p. 169-176, 2007.

ROJAS-ARÉCHIGA, M.; VÁSQUEZ-YANES, C. Cactus seed germination: a review. Journal of Arid Environments, v. 44, p. 85-104, 2000.

ROJAS-ARÉCHIGA, M.; CASAS, A.; VÁZQUEZ-YANES, C. Seed germination of wild and cultivated Stenocereus stellatus (Cactaceae) from the Tehuacán-Cuicatlán Valley, Central México. Journal of Arid Environments, v. 49, p. 279-287, 2001.

SIMÃO, E.; SOCOLOWSKI, F.; TAKAKI, M. The epiphytic Cactaceae Hylocereus setaceus (Salm-Dick ex DC.) ralf bauer seed germination is controlled by light and temperature. Brazilian Archives of Biology and Technology, v. 50, n. 04, p. 655-662, 2007.

SOUZA, V. C.; LORENZI, H. Botânica sistemática: guia ilustrado para identificação das famílias de Angiospermas da flora brasileira. Nova Odessa, SP: Instituto Plantarum, 2005. 639 p.

TAYLOR, N. P.; ZAPPI, D. C. Cacti of Eastern Brazil. Royal Botanic Gardens, Kew. 2004. 499 p.

VIEIRA, D. C. M; SOCOLOWSKI, F; TAKAKI, M. Germinação de sementes de Dyckia tuberosa (Vell.) Beer Bromeliaceae) sob diferentes temperaturas em luz e escuro. Revista Brasileira de Botânica, v. 30, n. 02, p. 183-188, 2007. 